\title{
LA ACCIÓN DEL PODER PÚBLICO SOBRE EL PRIVADO: LA NORMATIVA SOBRE SALEDIZOS Y BALCONES EN LA CIUDAD DE VALENCIA EN EL SIGLO DE LAS LUCES.
}

\author{
The Action of the Public Power over \\ the Private: the Rules on Cantilevering \\ of Features and Balconies in the City \\ of VAlenCia (1238-1796).
}

\author{
Paolo Privitera
}

RESUMEN: A pesar de haber sido vedados por los primeros Fueros de Jaime I y por las normas renacentistas castellanas entradas en vigor después del Edicto de la Nueva Planta (1707), todavía a mediados del siglo XVIII saledizos y balcones volados sobre la calle pública representaban un problema para la capital del Turia. Efectivamente, las dimensiones de estos elementos llegaban a veces a imposibilitar el uso de las calles a los transeúntes o a ponerlos en peligro a causa de las pobres condiciones de conservación de las estructuras. Este estudio, basado en fuentes inéditas del Archivo Histórico Municipal de Valencia, relata el desarrollo de los instrumentos legales del poder administrativo de la ciudad de Valencia para contrarrestar una situación de ilegalidad difundida y arraigada con el fin de reubicar el interés público por encima del privado.

Palabras clave: balcones, Valencia, saledizos, Tribunal del Repeso, Archivo Histórico Municipal de Valencia. 
AbSTRACT: Banned by the first Privileges of James I and by the Castilian Renaissance rules enforced after the Nueva Planta decrees (1707), still in the middle of the eighteenth century, overhangs and balconies over the public street were a problem for the city of Valencia. Indeed, the dimensions of these elements sometimes made impossible for transients to use the streets or they endangered people because of the poor conditions of those structures' maintenance. This study, based on unpublished sources from the Municipal Historical Archive of Valencia, relates the development of the legal instruments of the administrative power of the city of Valencia to counteract a situation of widespread and entrenched illegality in order to relocate the public interest over the private one.

Key words: balcony, Valencia, cantilevering constructive features, Tribunal del Repeso, Archivo Histórico Municipal de Valencia.

\section{INTRODUCCIÓN ${ }^{1}$}

En la época de dominación árabe hay que considerar que la reglamentación sobre la distribución y posición de los edificios dependía en gran medida del Muhtasib, quien básicamente velaba por la convivencia común entre vecinos y, por regla general, se permitían todas las variaciones que no estorbaran a esta, respetando la regla de la hisba. Además, desde el comienzo de la conquista cristiana, los territorios árabes ibéricos, debido a la migración masiva hacia zonas más alejadas de la pujante frontera, sufrieron un progresivo aumento de población que facilitó una mayor permisividad de la hisba sobre los aspectos de ocupación de los espacios públicos y sobre la proliferación de los elementos volados. ${ }^{2}$

Evidentemente, el incremento de la densidad habitacional urbana fue aumentando progresivamente a medida que los territorios de los reinos islámicos iban reduciéndose, por lo que se puede imaginar que las ciudades conquistadas durante la primera mitad del siglo XIII estarían mucho menos densificadas que las ciudades del Reino de Granada.

Torres Balbás sostiene que las viviendas de las ciudades hispanomusulmanas anteriores a las últimas décadas del siglo xıII se caracterizaban por la ausencia de vanos abiertos al exterior y, en caso de haberlos, se trataría de va-

1. Este estudio forma parte de la tesis doctoral titulada El balcón y el mirador en la arquitectura premoderna: el caso de la Valencia intramuros. Estudio histórico compositivo y de cultura material, defendida en abril de 2015 en la Universitat Politècnica de València. Acerca de algunas elucubraciones del presente texto se quiere agradecer la disponibilidad del Prof. Sergio Emiliano Villamarín Gómez, del Departamento de Derecho Financiero e Historia del Derecho de la Universitat de València.

2. Ricardo Anguita Cantero: Ordenanza y Policía urbana: los orígenes de la reglamentación edificatoria en España (1750-1900), Universidad de Granada, Granada, 1997, p 36. 
nos de pequeñas dimensiones y con una distribución irregular en la fachada. Continúa afirmando que solo a finales del siglo XiII se desarrollaría un nuevo tipo de composición con cuerpos salientes respecto al plano de la fachada para aumentar de una forma admisible el espacio interior de la vivienda. ${ }^{3} \mathrm{Sin}$ embargo, en la Valencia ocupada de 1238, la proliferación de los elementos volados fue puesta en evidencia directamente por el mismo Jaime I, quien, con el fin de permitir la penetración de la luz solar hasta la calzada, obligó a que «nadie pueda hacer casa, habitación, porche, saliente o voladizo sobre camino o plaza pública». ${ }^{4}$

La resignificación que sufrieron las ciudades hispanomusulmanas mediante una activa damnatio memoriae de los vestigios de la dominación anterior se dirigió en un primer momento a los voladizos, ordenando su destrucción completa, ya que la reconstrucción de la trama urbana supondría un gasto demasiado elevado y la estrechez de las calles islámicas no se adaptaba al uso de las poblaciones cristianas. Con fecha del 7 de julio de 1501 encontramos la primera Carta Real para el derribo de balcones y ajimeces en la recién ocupada ciudad de Granada, seguida por otra del 29 de Junio de 1503, en la que se puede leer:

Por parte de la dicha cibdad nos fue hecha relación diciendo que las calles desa dicha cibdad de Granada en muchas partes son angostas, è que seria muy útil è provechoso para el bien è procomún de la dicha cibdad è hornato della que los balcones è aximezes de las dichas calles se derrocasen, è nos fue suplicado è pedido por merced vos diésemos licencia è facultad para derrocar los dichos balcones y aximezes, ò que sobrello mandásemos proveer como la nuestra merçed fuese, lo qual visto en el nuestro consejo, fue acordado que deviamos mandar dar esta nuestra carta en la dicha razón, è nos tovimoslo por bien, porque vos mandamos que luego veades lo suso dicho y cerca dello proveays que vos paresciere que se debe proveer, para el bien è procomún e honrato desa dicha cibdad de Granada en los lugars mas públicos è mas nesçesaruis della. ${ }^{5}$

El problema de los saledizos en la vía pública no se resolvió, empero, durante el siglo XVI. La necesidad del derribo completo y total de los pasadizos, saledizos y balcones en las ciudades del Reino de Castilla se repite en 1530 en una ley de Carlos I con fecha del 28 Junio de 1530, que se encuentra recogida a principios del siglo XIX en la Novísima Recopilación solicitada por Carlos IV.

3. La teoría de Leopoldo Torres Balbás expuesta en su Ciudades hispanomusulmanas viene respaldada por Aurora García Uyarra; Ángel González Benito y José María Justo Moreno: La casa en España I. Antecedentes, Cuadernos de la Dirección General para la Vivienda y Arquitectura, Madrid, 1987, nota 8.

4. Libre I, Rubrica II, Fur xxiv recopilado por Francisco TABerner PAstor: Valencia entre el ensanche y la reforma interior, Edicions Alfons el Magnanim, Valencia, 1987, p. 23.

5. Archivo Histórico Ciudad de Granada: Libro Primero de Provisiones del Archivo de esta M. N. C. que contiene reales cédulas, pragmáticas y privilegios de S. M. concedidas a Granada, que comprenden desde el año 1490 hasta el 1544, fol. 84 r. Carta para derribar los ajimeces, dada en Granada el 7 de Julio de 1501. Recogida en el apéndice documental de Rafael López Guzmán: Tradición y Clasicismo en la Granada del XVI: Arquitectura civil y Urbanismo, Diputación Provincial, Granada, 1987, Biblioteca de Ensayo n. ${ }^{\circ} 10$. 
Novísima Recopilación. Libro vir. Titulo xxxir. De la Policia de los Pueblos. Don Carlos I y Da Juana en Madrid à 28 de Junio de 1530.

Prohibicion de balcones, pasadizos y otros edificios que salen de la parede de las casas a las calles.

Mandamos, que agora ni de aquí adelante ninguna ni algunas personas, de qualquier estado ó condicion, preeminencia ó dignidad que sean, no hagan ni labren, ni edifiquen en las calles públicas de las ciudades, villas ni en alguna dellas pasadizos ni saledizos, corredores ni balcones, ni otros edificios algunos que salgan á las calles fuera de la pared era quese hiciere el tal edificio: y de aquí adelante si alguno ó algunos de los pasadizos y balcones, y saledizos y corredores y otros edificios de los suso dichos, que en las calles desas dichas ciudades y villas estan hechos y edificados, se cayeren ó derribaren, ó desbarataren por qualquier manera; mandamos, que los dueños de las casas donde estuvieren hechos, ni los que en ellas moraren, ni otras personas algunas los non puedan tornar hacer ni reedificar, ni renueven ni adoben ni reparen; y quando fueren caidos todos ó qualquier parte dellos, que no lo tornen hacer, ni reedificar ni reparar cosa alguna ni parte dellos, salvo que quede raso é igual con las dichas paredes, que salen á las dichas calles donde estuvieren los tales edilicios; por manera que las dichas calles públicas queden exentas sin embargo de ningun pasadizo ni saledizo, ni otro edificio alguno de los sobredichos, y eesen alegres y limpias y claras, y puedan entrar y entren por ellas sol y claridad, y no cesen los dichos provechos; so pena que los que hicieren los sobredichos edificios, y los reedificaren y adobaren, que luego les sean derribados, y por el mismo hecho no los puedan tener ni hacer mas; y demas allende incurran y cayan en pena de diez mil maravedís, la mitad para la nuestra Cámara, y la otra mitad para el acusador. (ley 8. tit. 7. lib. 7. R.).

Sin embargo, aunque con la ley de 1530 quedara completamente prohibido cualquier vuelo desde la fachada de los edificios, la realidad era que los elementos vedados heredados desde la Baja Edad Media se siguieron manteniendo en toda la época moderna sin demoliciones, a menos de casos muy estorbadores. Además, hasta mediados del siglo XviII se fueron añadiendo nuevos saledizos. Es paradigmático el caso presentado por Tovar Martín en El pasadizo, forma arquitectónica encubierta en el Madrid de los siglos XVII y XVIII, donde se demuestra la eficacia real de la normativa real sobre los saledizos. En 1763, el Marqués de Montealegre, mayordomo de su majestad, pide permiso para construir un pasadizo. Hacía poco más de dos siglos habían sido absoluta e inequivocablemente vedados, por lo cual el duque de Arcos añade al informe parte de la ley de 1530 para recalcar la ilegalidad de la obra. El marqués, a pesar del informe, obtendrá la licencia para construir su pasadizo. ${ }^{6}$

6. Virginia Tovar Martín: «El pasadizo, forma arquitectónica encubierta en el Madrid de los siglos XVII y XVIII», en Villa de Madrid, XXIV, 87, 1986, pp. 31-42. 
Esta velada anarquía respecto a las leyes reales dependía de una situación legal típica del Antiguo Régimen: un panorama normativo enredado, con competencias legales superpuestas e interconectadas que dejaban margen a vacíos legales y, sobre todo, a vacíos administrativos. Para obtener un cuadro más realista hay que considerar, además, la falta de medios de promulgación realmente eficaces - por lo que fácilmente se hacía recurso con la excusa de la ignorancia de la normativa-, la dificultosa consulta del corpus legislativo en vigor -que no se agilizó hasta la llegada de las recopilaciones-, o la prevalencia de la legislación particular, entre otros factores.

Además, en el caso de los saledizos y de los balcones es posible que, aunque vigente desde 1530, la normativa simplemente no se aplicara por la incapacidad del poder real de obligar a su cumplimiento, ya que en las propias sedes de gobierno eran presentes tales elementos vedados y su supresión obligaría a un gasto público que las instituciones no estaban dispuestas a sostener.

Efectivamente, los palacios gubernamentales asentados en las plazas mayores de los centros urbanos castellanos, ya a partir del siglo XVI, incorporaron el balcón en sus fachadas con fines representativos para utilizarlos como palcos de honor durante las festividades. Resulta claro entonces como la aplicación de la normativa que vedaba el uso de tales elementos en la edificación privada tuviese muy poca factibilidad.

\section{El Siglo de las luces y la Nueva Planta}

La ruptura de los esquemas preestablecidos permitió, entre otras cosas, el advenimiento de una clase social, la burguesía, que fue cobrando consciencia y valor a lo largo del siglo, llegando a sublevarse en acciones como la Revolución francesa. La sociedad fue tomando conciencia de que la realidad contingente, paso a paso, se puede ser modificar y mejorar de muchas formas, incluso luchando. Cobra entonces sentido el experimentalismo utópico de los arquitectos franceses verdaderos neoclásicos, como los definió Javier Hernando, ${ }^{8}$ que, superando la teoría de los órdenes, se sumergieron en el mundo de la arquitectura de las formas puras, de las geometrías euclídeas. Entre estos arquitectos académicos, Boullé y Ledoux encarnaron el espíritu de la razón libre e interrogativa. De una forma empírica, los estados nacionales, así como los ayuntamientos, comenzaron un proceso de desincrustación y activación para mejorar la situación contingente en la que se encontraban. Según el mayor o menor grado de libertad de pensamiento mental adquirido por la población, las transformaciones de determinados países fueron más o menos rápidas.

7. Luis Gordo Peláez: «Balconies for the Municipalities: Public Architecture and Visual Performance of Power in Early Modern Castile», en Potestas, revista del Grupo Europeo de Investigación Histórica, 5, 2012, pp. 193-218.

8. Javier Hernando Carrasco: Arquitectura en España 1700-1900, Cátedra, Madrid, 1989, cap. 1. 
Estados como España se encontraron en una situación desfavorecida porque, a falta de una clase burguesa suficientemente rica y numerosa, la nobleza tomó un papel que no le correspondía, encarnando el espíritu de una pseudorenovación que, emulando a la francesa, no consiguió germinar en la sociedad española.

El análisis de la normativa urbana del siglo XviI sobre aspectos importantes como los elementos volados sobre la vía pública es, en definitiva, una historia de la estrategia estatal para inocular y hacer entender el concepto de que la utilidad pública supera las necesidades del individuo, sea quien sea este individuo. Los ayuntamientos fueron desarrollando, a base de tentativas, ciertas capacidades resolutivas, así como una serie de habilidades para tratar de encontrar las formas más eficaces para que todos las respetasen, tanto los nobles como los pobres, los clérigos como los militares. En lo que concierne a los saledizos y los balcones, con el Edicto de Nueva Planta, la ley Real de Carlos I de 1530 entró en vigor de forma automática en el Reino y en la ciudad de Valencia.

\section{LOS SALEDizos}

La primera referencia a esta ley se encuentra en las Actas del Consell ${ }^{9}$ del 21 de Octubre de 1751, cuando se registra la llegada al ayuntamiento de la ciudad de una Carta Real, de fecha 8 de octubre de 1751, firmada por la Real Audiencia, en la que se pone manifiesto que:

...lo dispuesto en la Ley octava, titulo siete, libro siete de la recopilación en que expresamente se prohibia que no se hiceran, labrase, ni edificasen en la Calles públicas d las Ciudades, Villas, y Lugares, ni en alguna de ellas, Pasadizo, Saledisos, Corredores no otros edificios, que saliesen fuera de la pared en que se edificase, y que si alguno, o algunos de dicho Pasadizos, Saledizos, y Corredores que estubiesen hechos y edificados se cayesen, derribasen o desbaratasen en qualquier manera, no se podiessen bolver a hazer reedificar, renovar, ó adornar, ni reparar en todo, ni en parte alguna de ellos, sino es que los edificios huviesen de quedar rasos è iguales con las paredes que salen alas Calles en que estubiesen aquellos bajo la pena àlos que contraviniesen de verles luego derrivados y de diezmil maravedis, se seguian en perjuicio de la publica utilidad los incovenientes que tubo bien presentes la misma ley del Reino de no estas las Calles, y Plazas, con la alegria, claridad, y limpieza que se requeria; Y que atendiendo igualmente a la experiencia manifestaba que mas que en otras algunas de nuestra España, se padecían esos perjuhicios en nuestra dicha Ciudad; Sobre domo de no inferior cosinderacion de haverse estrechado muchas de las calles con dhos Salidizos, y Pasadores de Puente, que apenas podian las Cassas recivir la luz que era suficiente para vivir comodamente en ellas, sin otros muchos em-

9. Libros de Actas, año 1751, D-89, f. 439-444, Archivo Histórico Municipal de Valencia (AHMv), 
barazos, que se observaban, y hacían cada día mas intolerables por la inaccion, ò descuydo de los passados, y porno haverse dedicado aquella correspondiente atención que se debía a un asumpto que de su naturales podrá enessa dha ciudad las mas particular, y distinguida para reparar por este medio la mala situaciones de su fundacion en la formacion de la calle, y Plazas. ${ }^{10}$

Lo primero que salta a la vista es que en la citación de la ley de Carlos I desaparece la referencia a los balcones, reduciendo el campo de acción de la ley real a pasadizos, saledisos y corredores que evidentemente se consideraban un problema más grave y que necesitaba más urgente solución. La situación en Valencia, donde los saledizos habían llegado a oscurecer las calles y a estrecharlas tanto que no se podían transitar, era bastante común en España, como ya se ha comentado, por la fundación árabe, orgánica y laberíntica, de muchas ciudades.

El drástico cambio de rumbo en la gestión de la cosa pública entró en conflicto con los derechos adquiridos y mantenidos ilegalmente durante siglos por parte de algunas porciones privilegiadas de la sociedad. La resistencia opuesta a la aplicación de las normativas resultó en algunos casos tan embarazosamente despótica, que la respuesta de las instituciones se tiñó de un tono que se podría definirse incluso como vengativo.

Un ejemplo de este tipo de casos lo encontramos en la Carta Real del 8 de octubre de 1751, donde se lee que su escritura se debió a un caso de «resistencia» que había llegado hasta la misma corte real: el intento del clero de San Juan del Hospital de oponerse al derribo de un saledizo de un edificio de su propiedad frente al palacio del Arzobispo. Los juaninos, orden rica y potente hoy como entonces, abrieron una batalla legal sin precedentes:

... por que aviendose quejado el Clero, y pretendido la revocacion de lo mandado, denegada su Suplica, apeló, y admitida la apelación en el efecto devolutivo solamente con formal Declaracion de no haber lugar aêlla en lo suspensivo, se presentó por via de Recurso a nostra Real Audiencia. ${ }^{11}$

Es evidente que el recurso del clero esperaba agarrarse a algún desentendimiento burocrático o a algún funcionario que necesitase el favor de esta orden y estuviera dispuesto a arenar el caso, ya que apelar a la Real Audiencia para recurrir a la infracción de una ley real no parecía un paso legal demasiado acertado. Se había desenterrado una lucha de poderes: los derechos seculares de la Iglesia contra el orden público. La Real Audiencia no se dejó intimidar y, consciente de no poder crear un precedente legal al cual todos los infractores pudieran apelarse, respaldó al ayuntamiento:

10. Libros de Actas, año 1751, Leg. D-89, f. 439-440, AHmv.

11. Libros de Actas, año 1751, Leg. D-89, f. 441, AHMV, 
... esta no expresada novedad [recurrir a la Real Audiencia] sorprendió justamente a la Ciudad, no tanto por ser ella admitida la apelacion que unas provicendias que por ser puramente gubernativas, y dirigidas a la execución de una Ley formal del Reyno, parecia era claro que no la admitirían en el Efecto suspensivo [...] porque una Vez abierta la Puerta en esta materia para hazerla contenciosa, y por el medio de las apelaciones mantener los interesados las Obras de dhos salidizos, Pasadores è edificios que resistían nuestra Leyes Reales, no bastaría todo el desvelo del Magistrado, ni mucha parte de las rentas de esta dicha Ciudad para acudir y sistener los Pleytos, q.e con este motivo se sucitarian todos los dias. ${ }^{12}$

La batalla del clero juanino resultó una derrota completa: la carta de la Real Audiencia sirve de forma general para insistir sobre la inapelabilidad de una ley real, ley que tenía que ser respetada y que los ayuntamientos estaban obligados a hacer respetar en sus términos; por otra parte y de forma particular, la carta trasmite al ayuntamiento de Valencia la resolución final a la cuestión del edificio en plaza del Arzobispo y de otros casos parecidos de los que posiblemente los abogados de los juaninos habían informado a la Real Audiencia:

... os mandamos, que luego que la recivais [la carta], observeis, y hagais se Observe rigurosamente la ley Octava, Titulo siete, Libro siete de la Recopilacion, [...] Y asimismo os mandamos hagais se derrive, no solo el que ha redificado el refereido Clero de San Juan del Hospital, sino tambíen el que en el año proximo pasado frente la Cassa enqueestá el Oficio del Repeso, que es la del lado de las Carnicerias principales con Vuestro permiso deshizo, y bolvió a reedificar de nuevo Vicente de Liucas Maestro Platero Al que enel año de quarenta, y nueve permitisteis en la calle de Serrans en una casa de un Javonero Parroquia de San Bartholome: en otra de dho Clero situada junto âla esparteria: Y tambien en otra de la Plaza publica,ò Mercado junto âlas estacas, frente âlas Casas del Conde de Alcazar; y demas de su Classe y circumstancias, y de haverlo executado así, remitereis al nuestro consejo, pormano de Dón Juan de Penuelas, testimonio de Camara, y de Gobierno, testimonio en el preciso termino de dos meses, con encargo especial queos haremos, de que en adelante, no permitais ni tolerei semejantes obras. ${ }^{13}$

Se trató de una sentencia general que, si bien por un lado respaldaba al ayuntamiento en la cuestión puntual del clero de San Juan, por otro lado entraba con fuerza en la gestión urbana, desautorizando licencias concedidas en el pasado por el mismo ayuntamiento. El gobierno estatal intentó hacer de alguna forma «borrón y cuenta nueva» con el fin de liberarse de antiguas deudas informales y poder aplicar sin recelos la normativa vigente, igual para todos y a favor de la comunidad.

12. Libros de Actas, año 1751, Leg. D-89, f. 442, AHMV.

13. Libros de Actas, año 1751, Leg. D-89, f. 443, AHмv. 
Aunque formalmente cerrada, la cuestión de los saledizos se mantuvo abierta en Valencia hasta la primera del siglo xix. El control urbano iba haciéndose más cerrado, pero difícilmente se podía imaginar una violenta aplicación de la normativa a todos los edificios de la ciudad que presentaran un saledizo. Por esta razón, bajo el control del ayuntamiento, la normativa real se aplicó de forma blanda, no derribando los muchos saledizos existentes, pero obligando a derribarlos en cuanto se desgastaran. Las características constructivas de la mayoría de tales elementos no eran de buena calidad, de manera que la actitud del ayuntamiento tenía en perspectiva una resolución ganadora: no se creaba malcontento y los saledizos se extinguirían de los frentes urbanos paulatinamente.

Todavía en 1774 se tiene constancia documental de reconocimientos de algunos saledizos por parte de veedores del Tribunal del Repeso, y las resoluciones no son completamente atentas a la normativa vigente. Es el caso de la casa del Maestro Platero Antonio López, propietario de la casa en calle de la Platería esquina con la calle ancha de la Platería, donde acudieron los veedores Rafael Morata y Lorenzo Martínez el día 7 de septiembre de 1774. En su relación al tribunal estos dijeron que:

... habiendo practicado el reconocimiento con toda reflexion y cuidado, no habían hallado peligro alguno en el total de dicho Salidizo, si solo en algunos ladrillos de las Baxdas que devian quitarse y que el pilar y pared medianera de dicha Casa y la del lado que es propia de Mosen Fran.co Escrich Beneficiado de la Metropolitana Iglesia de esta Ciudad se hallavan con notable peligro y que por el porjuuycio q.e al publcio podía resulta de la ruyna de dicha pared y Pilar devia acudirse a su reparación. ${ }^{14}$

Es decir, Antonio Platero se quedó con su saledizo, ilegal, pero de seguridad certificada. En el mismo año encontramos otro caso: la visura hecha el 19 de Julio de 1774, en calle del Milagro de San Vicente junto a la Platería.

... havian hallado q.e el Salidizo q.e hay en dha calle estaba desecho y derrivado; y q.e reconoda la pared maestra bajo dho Salidizo hallaron estas vencida a la Calle un palmo y cinco dedos, y q.e sobre ella cargava un pilar q.e sostiene las Iacenas del desván y terrados de la casa; Y comprendías q.e para evitar todo peligro se devia de demoler, apeando antes todo lo q.e sea menester. ${ }^{15}$

En este caso, la dueña es informada solo de que es su obligación derribar la pared de la fachada. Una vez derribada, aunque no consta en el expediente, tendrá que pedir permiso para volverla a construir, y entonces se tendría que

14. Policía Urbana, año: 1774, caja 3, expediente 156, Aнмv.

15. Ídem. Estos dos casos se encuentran recopilados en el «Expediente formado de Oficio por el S.r D.n Mauro Antonio Oller, y Bono otro de los Cavalleros Regidores fieles executores de Repeso en el mes de Julio sobre reconocim.to de salidizos, y provacion de rehedificarlos en conformidad de las Ordenes superiores q.e hay comunicadas à este Oficio del Repeso» 
acoger a la línea de la fachada, sin volar ningún elemento a la calle. Esto, por supuesto, en caso de hacer las obras pidiendo permiso legal.

Los últimos expedientes que se encuentran son de mitad del siglo XIX conciernen a la demolición definitiva de los saledizos y, en un caso concreto, a la denuncia por parte de la autoridad municipal de un refuerzo hecho con unas pletinas de hierro al vuelo de uno de ellos. ${ }^{16}$

\section{LOS BALCONES}

Aunque legalmente unidos con los saledizos, pasadizos y corredores por la ley de 1530 de Carlos I, los balcones no fueron acomunados a estos en la práctica de los ayuntamientos; la misma Real Audiencia, en la carta del 8 de Octubre de 1751, hace caso omiso de la presencia de los balcones en la referida ley renacentista.

La primera referencia normativa que se ha podido encontrar en tema de balcones en Valencia tiene fecha del 30 de mayo de 1758. Se trata del Auto de Buen Gobierno de «Don Joseph De Avile» ${ }^{17}$ en el que aparece una breve pero importante referencia que demuestra el interés del ayuntamiento por el control de los vanos de las fachadas y, así, por la buena composición de estas.

[...]Añadiendose à esta providencia, que los expressados Maestros, y Oficiales Albañiles, que fabricaren alguna casa de nuevo, ò repararen el frontespiscio de ella, no lo puedan executar sin dar cuenta al Tribunal del Repeso; y éste á su Señoria, para la uniformidad de los balcones, y ventanas, igualmente para la altura de sus casas, y rectidud que deven llevar con las calles. ${ }^{18}$

Según el auto, el clavario del Gremio de Albañiles habría tenido que informar a todos los maestros y oficiales del gremio de las normas impuestas por el corregidor en el año 1758, dando inicio a un control eficaz sobre las construcciones que se quisieran ejecutar en la ciudad. Pero no fue así, y en 1760 se registraron varias denuncias por unos balcones aparecidos en la plaza del Mercado sin licencia del Tribunal del Repeso, que estorbaban el paso y el cómodo uso de la plaza más vivaz de la ciudad. A raíz de este evento D. Juan Pedro Coronado, Corregidor en 1760 , se vio obligado a instar otro auto, esta

16. Policía Urbana, año 1808, caja 105, expediente 27, AHMV.

17. Policía Urbana, año 1758, caja 1, expediente 31, Aнmv. Se trata de un auto que normativiza varias temáticas sobre la gestión y la vida de la ciudad con el fin de asegurar la limpieza y la seguridad de las calles para toda la ciudadanía. Se habla así de la limpieza del trozo de calle delante de cada vivienda, de las tasas que tienen que pagar los carros que entran en la ciudad, de la recogida de basura de las viviendas, así como de los restos desechables de los talleres. La parte normativa más contundente trata sobre la organización y la seguridad de las obras en la ciudad, sobre cómo deshacerse de los escombros o cómo tienen que ser protegidas con vallas las mezclas de cal si se dejan en medio de la calle, entre otras cosas.

18. Ídem. 
vez dirigido única y exclusivamente a los maestros y oficiales del Gremio de Albañiles. ${ }^{19}$

Los responsables del casus belli de la plaza del Mercado fueron identificados y castigados; sin embargo, muchos de los maestros entrevistados afirmaron, posiblemente en apoyo a los culpables, que la normativa de 1758 no era fácil de entender. Juan Pedro Coronado, no pudiendo rebatir a la ridícula respuesta del gremio y queriendo cerrar la cuestión sin que esta se repitiera más veces, contestó con una normativa más larga y más detallada. Esta vez, empero, pidió que en el término de 24 horas ${ }^{20}$ el clavario del gremio le entregase una lista de todos los maestros de obra avisados y que estos, con sus firmas, confirmaran haber entendido la normativa. En la nueva normativa se impone una pena de 50 maravedís y rigurosa prisión por no presentar la solicitud de permiso al Tribunal del Repeso y atenerse a las indicaciones por él dadas. El expediente se cierra con la lista de las firmas de los maestros.

... à cuyo fin, y el de evitar la ordinaria disculpa de falta de noticia, ô inteligencia, se notificara la presente al Clavario del referido Gremio de Alvañiles para que por medio de este se haga notorio â todos los individuos de èl en el preciso termino de veinte y cuatro horas y pasado este deverá comparecer ante su Señoria, y el presente Escrivano â manifestar haver hecho notoria â todos los congregados Un dividuos de dicho Gremio esta Providenvia, expresando sus nombres y apellidos para que en todo el tiempo conste esta Diligencia que para servir de fundamento al procedimiento contra los contraventores de ella. ${ }^{21}$

Aparte de la interesante nota sociocultural que demuestra el juego de poder y la astucia del corregidor para imposibilitar futuras falsas excusas, este auto aporta un dato muy interesante sobre la evolución normativa de los balcones:

... mandó que los Maestros y Oficiales Alvañiles de esta dicha Ciudad, con ningun pretesto ô motibo, puedan de dia ni de noche, poner en la referida Plaza del Mercado ni calle de ella Balcón alguno viejo ni nuevo, de hierro ô de madera sin haver antes dado cuenta â dicho Tribunal del Repeso. ${ }^{22}$

Esta sentencia pone de manifiesto que en 1760 los balcones de madera eran todavía legales en la ciudad de Valencia. Serían las normativas posteriores a estas fechas las que iniciaron la lenta supresión de los balcones de madera en

19. Policía Urbana, año 1760, caja 1, expediente 36, AHмv.

20. Resulta interesante anotar la rapidez con la cual el regidor quiere cerrar la cuestión: efectivamente en el caso del terremoto de 1775, a los veedores de Tribunal del Repeso se dieron cuarenta y ocho horas para hacer la relación de los daños registrados en los cuatro cuarteles de la ciudad, mientras en este caso se trata únicamente de veinticuatro. Sobre el terremoto y las respuesta del gobierno de la ciudad véase: CAMILLA Mileto; Paolo Privitera; Fernando Vegas y Francesca Martella: «Un hecho olvidado: el terremoto del 15 de noviembre de 1775», en Arché, 6, 2011, pp. 303-308.

21. Policía Urbana, año 1760, caja 1, expediente 36, Aнмv.

22. Ídem. 
favor de los de hierro, más durables y seguros. En el análisis de los documentos de archivo se observa que no vienen definidos los materiales de construcción permitidos hasta que se impuso el balcón de hierro. No pudiendo definir la fecha exacta en la que el ayuntamiento de Valencia pasó a pretender la instalación de balcones exclusivamente de hierro, todos los datos que se puedan localizar a ese respecto resultan útiles para tratar de identificar la fecha de cambio. Tampoco en la nueva normativa madrileña se hace ninguna referencia al material de construcción, por lo que se puede suponer que los balcones de madera y de hierro fueran ambos legalmente aceptados.

\section{Capitulo XLII}

Delos buelos delas rexas, y halcones.

Siendo la calle estrecha, no se puede sentar ninguna rexa baxa, que buele Mas de quatro dedos, por el perjuicio de los pasajeros: y en caso que la calle sea ancha, y capaz, para que rueden dos coches á la par, y los lados, para que los de á cavallo, y á pie, puedan pasar: en tal caso, pueden las dichas rexas bolar medio pie. En quanto á los balcones, ò rexas boladizas, no se pueden sentar, sino es estando catorce, pies de alto, desde la superficie de la calle, hasta las carrelas de los balcones, ó rexas; y con tal altura, habrá capacidad, para poder pasar la gente deá cavallo, y los coches, sin estorbo, ni perjuicio; atendiendo, que el Alarife, no consienta, que se sienten los balcones, y rexas, sino es en acitaras de hasta, y frente, por lo plenos, por el mucho peso que carga sobre sus buelos, y seguros de la ruína que se promete. ${ }^{23}$

La normativa madrileña era más específica y, aunque no tratase de los materiales de construcción, reglamentaba claramente los vuelos permitidos, mientras que en Valencia habrá que esperar a 1778 para que se pueda encontrar constancia de un primer control dimensional reglamentado de los vuelos de los balcones sobre la vía pública. ${ }^{24}$

El Ramo de Providencia sobre esquinas, Rejas, Balcones y Alumbrados ${ }^{25}$ recopila varios autos del Consell de la ciudad, desde 1731 hasta 1792. El primero, de 1731, trata sobre los chaflanes en piedra que había que hacer en los edificios para facilitar el paso de los carruajes y consta de dibujos de las geometrías con las que se tenían que labrar las esquinas. El segundo auto recopilado es del 24 de abril de $1778^{26}$ y contiene las primeras noticias acerca de la reglamentación dimensional sobre los vuelos de los balcones.

23. JUAN DE TORIJA: Tratado breve de las ordenanzas de la villa de Madrid y Policía de ella, Imprenta de Antonio Pérez de Soto, Madrid, 1760.

24. Anteriormente a esta fecha, el vuelo de los balcones estaba controlado caso por caso por los veedores del Tribunal del Repeso, como se puede leer en Auto de 1760 en el que se especifica que, una vez pedido permiso al tribunal, habrá que construir el balcón «con la volada que se especifique en dicha licencia».

25. Policía Urbana, año 1731, caja 1, expediente 2, AHMv.

26. Policía Urbana, año 1731, caja 1, expediente 2, folio 7-9, AHMv. 
... sin permitir ... [que se]... coloquen fuera de la Pared Rexas, ni Balcones, aunque sea su figura ovada, hasta la distancia de nueve Palmos, entendiendose aun en aquellas Casas, ò edificios que se estén fabricando, no obstante que tengan ya permiso para ello del Tribunal del Repeso, ni otra obra por minima q.e sea, y haga salida de la Pared, dentro la referida distancia de los nueve palmos, baxo la pena al q.e contravenga de seis pesos de multa por la primera vez, y de executarse à sus costas, lo que se dispone por esta providencia en qualquier estado q.e se halle la obra: doble por la segunda, con la misma reposicion; y la tercera à voluntad de su Señoría. ${ }^{27}$

Este auto representa un primer tímido intento del ayuntamiento de acondicionar para el uso decoroso las calles de Valencia, actuando de forma contundente sobre los elementos arquitectónicos salientes. Es sabido que los primeros intentos nunca salen bien y, efectivamente, siendo el palmo valenciano de 22,65 $\mathrm{cm}$ (9 palmos $=203,85 \mathrm{~cm}$ ), con este auto se mandaba que el Tribunal del Repeso velase sobre la disposición de los balcones y las rejas de las plantas primeras y de los entresuelos, e impidiese la colocación de elementos volados solo por debajo de los dos metros de altura, medida reducida si se considera que la un hombre a caballo no hubiese podido pasar por debajo. Además, la normativa afectaba exclusivamente a los balcones que estuvieran instalándose en aquel entonces y tendría que aplicarse a los venideros, pero no se aplicaba de forma retroactiva a los balcones existentes. Si se compara con las ordenanzas de Madrid de 1760, la normativa valenciana resulta más inmadura, ya que no considera ni la diferente anchura de la calles, ni el paso de los hombres a caballo, obligando solo a aplanar todas las fachadas hasta la altura necesaria para el paso confortable de un hombre a pie, medida ergonómica que se declara en otro bando del 29 de Marzo de $1780 .{ }^{28}$

Este nuevo auto, más formal e incisivo que el anterior, encubrió su nacimiento bajo una falsa referencia a la Real Provisión del 8 de Octubre de 1751, que en realidad no trata de los vuelos de los balcones y de las rejas -contraviniendo a su vez a la ley de Carlos I que aunaba los saledizos y los balcones-. El auto de 1780 se refiere a:

Rejas bajas, Balconillos y otros Salidizos, que por no distar del Piso algo mas de la Estatura de un hombre incomodan y perjudican á los q.e transitan por las Calles, y Plaza en el preciso termino de un mes los hagan quitar y derribar: y en el caso q.e tengan por comveniente reponerlos o hacerlo de nuevo, sea de modo q.e de ninguna manera puedan causar daño. ${ }^{29}$

En este caso no se define una dimensión máxima de vuelo concedido ni se hace referencia al auto precedente, pero se introduce un término dentro del

27. Ibídem, folio 8 .

28. Policía Urbana, año 1731, caja 1, expediente 2, folio 11-12, Анмv.

29. Ibidem, folio 11 . 
cual la normativa tiene que ser respetada, además de introducir el concepto de «globalidad», al aplicarse sin distinciones a todos balcones, existentes y venideros. En definitiva, este auto aportaba algunas mejoras respecto al anterior, aunque su aplicación fue completamente imposible dado que vedaba que la «colocasion de Balcones, Rejas y mas estorvos se execute sin q.e Tenga la altitud, q.e manda el R.l Acuerdo», y este no hacía referencia ni a los balcones ni a sus dimensiones.

\section{LA INTERVENCIÓN RESOLUTIVA}

El proceso por tentativas sucesivas para encontrar una fórmula administrativa eficaz sobre las dimensiones de los vuelos de los balcones y de las rejas en la ciudad de Valencia irá tomando forma en la última década del siglo XVIII. Por no haberse todavía cumplido lo esperado con el bando de 1780, el día 2 de julio de 1792 el Corregidor D. Juan de Parefa, mandó que se publicara un nuevo bando:

... p.ra que las Rexas ô Balcones, q.e existen à la elevacion de nueve palmos de la superficie de la calle, y salgan de la linea de la pared, se retiren dentro el preciso termino de un Mes á la misma linea: Mando asimismo que dhas Rejas ô Balcones que desde los Nueve Hasta los trece palmos de elevacion, salgan de la pared mas de un palmo se reduzcan precisamente, dentro el proprio termino â esta medida; con apercibimiento de q.e Dicho Termino Pasado sin haverlo complido el Maestro Arquitecto Mayor de esta Ciudad, lo executará á costas del Dueño Respectivo (fig. 1). ${ }^{30}$

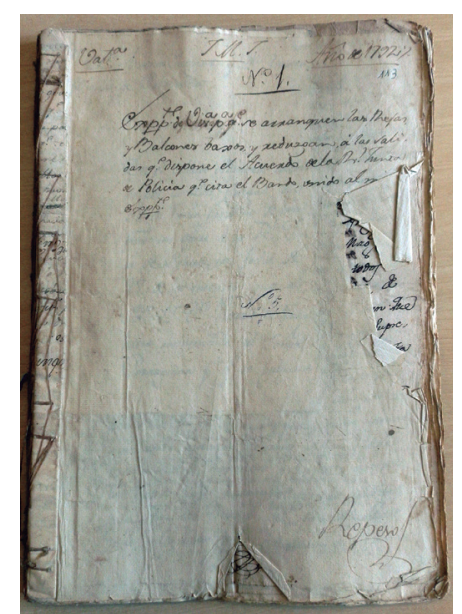

Fig. 1. Portada del expediente que conserva en su interior el bando del 2 de julio de 1792.

30. Policía Urbana, año 1792, caja 12, expediente 113 folio 3, AHMv. 
Esta vez se especificaron literalmente las medidas que se permitían para el vuelo de balcones y rejas, creando además una jerarquía de los saledizos, y superando la antigua franja de interés de los nueve palmos de altura. Con la norma así entregada, la ciudad de Valencia ampliaba la protección del espacio público, desde las medidas de un hombre a pie hasta las de un hombre a caballo o un carruaje, acercándose a unas dimensiones comparables con las de la villa de Madrid, que eran de catorce palmos, aun considerando la diferencia entre el palmo valenciano y el madrileño. Además, al igual que en 1780, se marca un término de tiempo concreto, un mes, para la ejecución de la reducción de los vuelos, superado el cual la reducción se ejecutará de oficio a costa del dueño. Este último acto intimidatorio, realmente no tuvo la repercusión esperada.

$\mathrm{Al}$ ser publicado este nuevo bando, ocurrió algo inesperado: D. Antonio Pascual, regidor perpetuo de la ciudad, para dar el buen ejemplo, se autodenunció:

... deseoso de ser de los Primeros en el cumplimiento de la sitada Providencia mande retirar a la linea de la Paret quatro balcones de los entresuelos de mi casa los dos en la parte que recae à la parte de San Vicente y los otros dos en la que se dexige la Plaza de la Capilla de la Comunion de la Iglesia Parroquial de S.n Martín à la Pescaderia sin embargo de que su salida era mui decor: ${ }^{31}$

Parece curioso ver a un político explicar su voluntad de estar entre los primeros en respetar una ley vigente, como mínimo, desde hacía doce años. Además, Antonio Pascual casi se justifica añadiendo ese «sin embargo de que su salida era mui decor». Pero dejando de lado la ironía, lo más notable de esta situación es el compromiso de un representante del Estado respecto a la comunidad de vecinos que gobernaba. Es posible que los efectos de la Revolución francesa y de las muchas cabezas empelucadas que estaban cayendo en las plazas de París -la de Luis XV cayó apenas en 1793- tuviesen cierto efecto de responsabilización en la nobleza a cargo de las ciudades. ${ }^{32}$

El 6 de agosto, pocos días después de acabarse el término preestablecido, se activó la máquina burocrática municipal. A diferencia de lo ocurrido con el bando de 1780, esta vez, acabado el término, se inauguró una campaña de controles generalizados por parte del Tribunal del Repeso. Se enviaron los veedores para que anotasen todos los transgresores en una «relacion clara, è, individual [...] notándolo por Manzanas, números de casas, y sus dueños para las demas providencias que correspondan». ${ }^{33}$

Esta vez, el ayuntamiento responde a los transgresores con un censo preciso y detallado de todos los elementos impropios que siguen instalados en la ciudad. A mediados de septiembre de 1792, los cuatro veedores entregaron los

31. Policía Urbana, año 1792, caja 12, expediente 113 folio 4, AHMV.

32. Para una visión sobre de los cambios y las evoluciones urbano-sociales durante la revolución francesa, véase Richard Sennett: Carne y piedra, Alianza, Madrid, 2010, pp. 302- 337.

33. Policía Urbana, año 1792, caja 12, expediente 113 folio 5, AHMv. 
resultados de sus visuras, dejando constancia documental de un estado relativamente caótico de las calles de la ciudad (fig. 2).

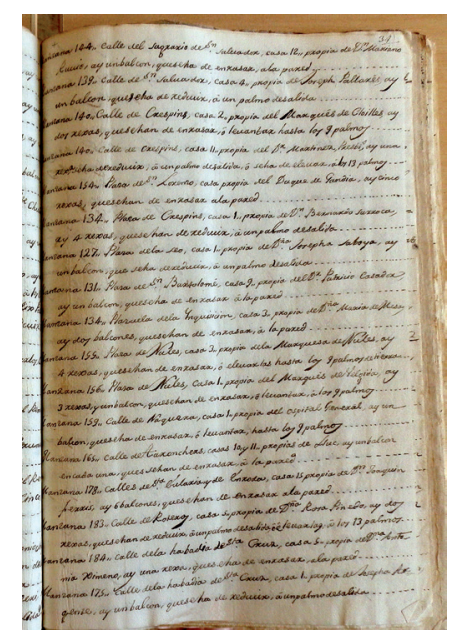

Fig. 2. Listado ejecutado en 1792 sobre los elemenntos con vuelo ilegal.

Para comodidad de análisis, los resultados de las visuras se han convertido en gráficos que demuestran que la distribución de los elementos ilegales no era homogénea en la ciudad. Los cuarteles de San Vicente, Mar y Mercado superan las ciento veinte denuncias, mientras el cuartel de Serranos llega solo a setenta y dos. Esto se debe a que el de Serranos era el cuartel menos densamente edificado todavía a finales del siglo XviII. ${ }^{34}$ Se evidencia de forma clara que las rejas y los balcones eran un estorbo numéricamente similar en los cuarteles de San Vicente, de Mar y de Mercado. Sin embargo, en el cuartel del Mar, zona que se encontraba entre las más estratificadas y opulentas de la ciudad, la presencia de un número elevado de edificios nobiliarios con entresuelos puede haber sido concausa del gran número de balcones ilegales contabilizados en las visuras. Efectivamente, los balcones del cuartel del Mar superan en porcentaje y en número los de los otros barrios de la ciudad, llegando a presentar denuncias de nueve balcones fuera medida en un solo edificio (fig. 3).

Un dato interesante que se deduce de la lectura de las visuras concierne al material de los balcones. Como se ha señalado anteriormente, se desconoce la fecha exacta en la que pasaron a ser ilegalizados los construidos de madera en la ciudad de Valencia. En dos casos, durante los reconocimientos de

34. Camilla Mileto; Paolo Privitera; Fernando Vegas y Lidia Soriano: «Construcción y transformación de la ciudad de Valencia. Datos de la historia construida a través de los documentos de archivo», en Actas del Séptimo Congreso Nacional de Historia de la Construcción, Instituto Juan de Herrera, Madrid, 2011, pp. 917-928. 
los veedores se apuntó el material de construcción del balcón: uno se mandó sustituir por uno de hierro por «amenazar ruina»; el otro se mandó sustituir por uno de hierro sin especificar nada más, ni siquiera si el de madera tenía las dimensiones ilegales. ${ }^{35} \mathrm{La}$ declaración del material, tan exacta y puntual, lleva a pensar que los demás balcones presentes en los listados eran de hierro, es decir, que los balcones de madera quedaban ya como una minoría. $\mathrm{O}$, por el contrario, se podría elucubrar que el porcentaje de balcones de madera era mucho más alto superados los trece palmos de altura. Lo que sí es cierto y se puede anotar como dato es que, en 1792, a razón de algún bando publicado en Valencia entre 1760 y 1792, los balcones de madera se ilegalizaron en favor de los de hierro.

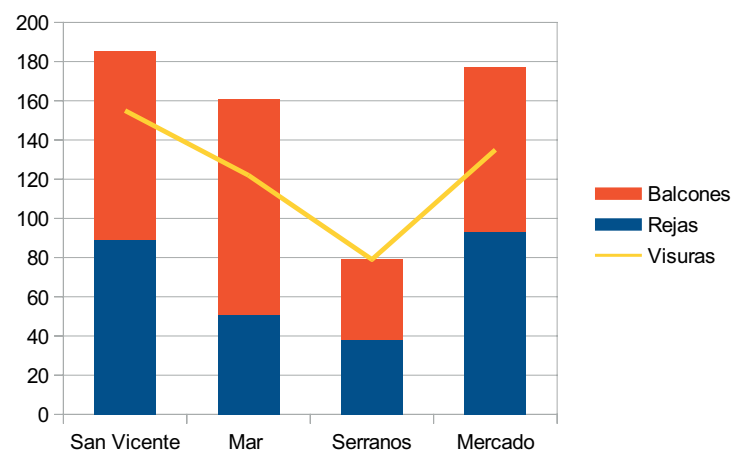

Fig. 3. Gráfico que demuestra las cantidades de elementos ilegales divididas por barrio, documentadas en 1792.

Una vez que los veedores entregaron las visuras, el tribunal protocoló el expediente, pero pocos días después, la máquina del control municipal se bloqueó. El expediente con todas las listas de transgresores pasó del Tribunal del Repeso al arquitecto mayor Lorenzo Martínez, con la orden de ejecutar la retirada de dichas rejas y balcones. ${ }^{36}$

El Tribunal del Repeso no dio más órdenes, no especificó la forma en que el arquitecto mayor tenía que ejecutar las retiradas ni el plazo en que debía hacerlo. Considerando las actuaciones anteriores, se puede afirmar que en particular la falta de un control temporal hizo que el expediente se volviera a

35. Policía Urbana, año 1792, caja 12, expediente 113, folio 65, AMHv. II ra revisión de Serranos (1796) Manzana 197, Calle Mesón de Morella, casa 11 propia de Felis Marin, ay un balcon de madera que amenaza ruina; deue quitarse y en su lugar poner uno de yerro con un palmo de salida. Y Policía Urbana, año 1792 , caja 12, expediente 113, folio 40, AmHv. Io revisión de Mercado (1792) Manza 413, Calle de Mallorquins casa 3 propia de la Viuda de Car??na, ay un balcon de Madera, se ha de quitar, y en su lugar, se ha de poner uno de hierro, con un solo palmo de salida.

36. Policía Urbana, año 1792, caja 12, expediente 113, folio 41, AMHV. 
encallar durante cuatro años. En este lapso de tiempo, Lorenzo Martínez no registró ninguna actividad sobre el expediente.

El siguiente documento es una orden de relieve. La Junta de Policía, habiendo pedido formalmente noticias sobre el avance de la tarea encargada al Arquitecto Mayor a primeros de marzo de 1796 y no habiendo recibido respuesta, devolvió el encargo al Tribunal del Repeso, dejando al Arquitecto Mayor la orden de pasarse por todas las casas de las listas cada quince días para recordar el bando a los infractores. En poco más de un mes, el tribunal desplegó todas sus fuerzas para asegurar el seguimiento del bando de 1792. Se mandó hacer un segundo reconocimiento para cotejarlo con el precedente y tener un censo preciso de quiénes habían ejecutado las reducciones y quiénes no. Para agilizar las tareas, y también para asegurar la incolumidad de los veedores, se crearon cuatro equipos de trabajo, uno para cada cuartel. Cada equipo contaba con un veedor y un portero del tribunal, quien tenía que avisar a los transgresores de que se les concedían solo tres días más para ejecutar lo mandado; de lo contrario, se ejecutaría de oficio y a su costa.

Las relaciones que se entregaron a finales de abril de 1796 firmadas por los veedores certificaban el reconocimiento de los elementos prohibidos y estaban acompañadas por una relación de los porteros que describían cómo había ido la tarea informativa. Francisco Bayot, portero del equipo del cuartel del Mar, comunica verbalmente al escribano de repeso que: «en el [el cuartel del Mar] havia muchos señores de la principal nobleza por cumplir y algo remitentes a ello, por lo que esperaba el tribunal acordase dha Real Junta que devia practicarse». ${ }^{37}$

De la misma manera que Vicente Puchol, portero destinado al barrio de San Vicente dice: «allanse remitentes algunos Cavalleros y sugetos de distincion al antesedente Oficio». ${ }^{38}$

De los otros dos barrios, el escribano no anotó nada, quedando solo las certificaciones propias de los porteros que se limitan a repetir una fórmula legal. Es importante anotar que esta ley se repercutía sobre los dueños de las casas sin afectar a los inquilinos, por lo que era de esperar que fuesen los nobles y los caballeros quienes se opusiesen más a esta normativa, no solo por ver atacados sus propios hogares, sino por las muchas casas de alquiler que probablemente tenían en la ciudad. Los dueños quedaron avisados de que pasados los tres días se pasaría a la ejecución de oficio, pero, lamentablemente, es entonces cuando el expediente se interrumpe. ${ }^{39}$

Desde un punto de vista descontextualizado, los porcentajes finales logrados por el Tribunal del Repeso en 1796 tras cuatro años de parón no parecen

37. Policía Urbana, año 1792, caja 12, expediente 113, folio 48, AMHV.

38. Policía Urbana, año 1792, caja 12, expediente 113, folio 61, AMHV.

39. La última traza documental que se ha encontrado de este proceso se encuentra en las Actas del Consell, que se remonta al 2 de Abril de 1796, (Libro Capitular, Actas 1796 d-179, AmHV.) fecha en la que se pidió copia de las antiguas visuras para proceder a crear las actualizadas. Se promueven futuras investigaciones para poder cerrar este interesante capítulo de la trasformación urbana de la ciudad de Valencia. 
de lo más satisfactorio: al realizarse la segunda toma de datos de control, quedaban todavía por arreglar poco menos del setenta por cien de los balcones y de las rejas ilegales.

Sin embargo, valorando el estado de la práctica administrativa de principios de siglo, la espiral de innovaciones que se desarrollaron, la genialidad con la que fueron multiplicándose las modalidades de actuación, cabe quedarse con el dato de un primer exitoso resultado de más del treinta por cien de actuaciones. Además, el siglo XVIII es en Valencia un momento de reciclaje de las construcciones urbanas. ${ }^{40}$ Las grandes obras de transformación, que acabarían con la mayoría de las fachadas y de los balcones ilegales presentes en el siglo XVIII, se llevaron a cabo a lo largo del siglo xix, bajo una normativa urbana más fuerte y entrenada, también gracias a las experimentaciones administrativas del Tribunal del Repeso durante el Siglo de las Luces.

\section{BibLIOGRAFÍA}

Anguita Cantero, Ricardo: Ordenanza y Policía urbana: los orígenes de la reglamentación edificatoria en España (1750-1900), Universidad de Granada, Granada, 1997.

De Torija, JuAn: Tratado breve de las ordenanzas de la villa de Madrid y Policía de ella, Imprenta de Antonio Pérez de Soto, Madrid, 1760.

García Uyarra, Aurora; González Benito, Ángel y Justo Moreno, José María: La casa en España I. Antecedentes, Cuadernos de la Dirección General para la Vivienda y Arquitectura, Madrid, 1987.

Gordo Peláez, Luis: «Balconies for the Municipalities: Public Architecture and Visual Performance of Power in Early Modern Castile», en Potestas, revista del Grupo Europeo de Investigación Histórica, 5, 2012.

Hernando Carrasco, Javier: Arquitectura en España 1700-1900, Cátedra, Madrid, 1989.

López Guzmán, Rafael: Tradición y Clasicismo en la Granada del XVI: Arquitectura civil y Urbanismo. Diputación Provincial, Granada, 1987.

Mileto, Camilla; Privitera, Paolo; Vegas, Fernando y Martella Francesca: «Un hecho olvidado: el terremoto del 15 de noviembre de 1775», en Arché, 6, 2011.

-; -; - Y SORIANO, LidiA: «Construcción y transformación de la ciudad de Valencia. Datos de la historia construida a través de los documentos de archivo», en Actas del Séptimo Congreso Nacional de Historia de la Construcción, Instituto Juan de Herrera, Madrid, 2011.

—: «La ciudad se construye sobre sí misma» en Camilla Mileto y Fernando Vegas: Centro histórico de Valencia. Ocho siglos de arquitectura residencial, La Imprenta, Valencia, 2015.

Sennett, Richard: Carne y piedra, Alianza, Madrid, 2010.

TAberner Pastor, Francisco: Valencia entre el ensanche y la reforma interior, Edicions Alfons el Magnanim, Valencia, 1987.

Torres Balbás, Leopoldo: Ciudades hispanomusulmanasi, tomo I, Instituto Hispano-Árabe de Cultura, Madrid, 1970.

Tovar Martín, Virginia: «El pasadizo, forma arquitectónica encubierta en el Madrid de los siglos XVII y XVIII», en Villa de Madrid, xxIV, 87, 1986.

40. Camilla Mileto: «La ciudad se construye sobre sí misma» en Camilla Mileto y Fernando VEGAS: Centro histórico de Valencia. Ocho siglos de arquitectura residencial, La Imprenta, Valencia, 2015, p. 86. 


\section{FUENTES INÉDITAS}

«Libros de Actas», año 1751, Leg. D-89, f. 439-444, Archivo Histórico Municipal de Valencia (AHMV).

«Policía Urbana», año 1731, caja 1, expediente 2, Archivo Histórico Municipal de Valencia (AHMV).

-: año 1758, caja 1, expediente 31, Archivo Histórico Municipal de Valencia (AHMv).

—: año 1760, caja 1, expediente 36, Archivo Histórico Municipal de Valencia (AHMv).

-: año 1774, caja 3, expediente 156, Archivo Histórico Municipal de Valencia (AHMV).

-: año 1792, caja 12, expediente 113, Archivo Histórico Municipal de Valencia (AHMV).

—: año 1808, caja 105, expediente 27, Archivo Histórico Municipal de Valencia (AHMv).

«Libro Capitular», Actas 1796 D-179, Archivo Histórico Municipal de Valencia (AHMV). 